Article

\title{
More Wind Power Integration with Adjusted Energy Carriers for Space Heating in Northern China
}

\author{
Hongyu Long ${ }^{1, *}$, Kunyao $\mathrm{Xu}^{2}$, Ruilin $\mathrm{Xu}^{3}$ and Jianjun $\mathrm{He}^{3}$
}

1 Postdoctoral Workstation of the Chongqing Electric Power Corporation, Chongqing 400015, China

2 Chongqing Electric Power Corporation, Chongqing 400014, China; E-Mail: xky_cqep@sina.com

3 Chongqing Electric Power Research Institute, Chongqing 401123, China;

E-Mails: xr186@163.com (R.X.); hejianjun70@163.com (J.H.)

* Author to whom correspondence should be addressed; E-Mail: h.y.long2008@hotmail.com;

Tel.: +86-23-6323-0486; Fax: +86-23-6323-0178.

Received: 13 April 2012; in revised form: 10 August 2012 / Accepted: 20 August 2012 /

Published: 31 August 2012

\begin{abstract}
In Northern China, due to the high penetration of coal-fired cogeneration facilities, which are generally equipped with extraction-condensing steam turbines, lots of wind power resources may be wasted during the heating season. In contrast, considerable coal is consumed in the power generation sector. In this article, firstly it is revealed that there exists a serious divergence in the ratio of electrical to thermal energy between end users' demand and the cogenerations' production during off-peak load at night, which may negate active power-balancing of the electric power grid. Secondly, with respect to this divergence only occurring during off-peak load at night, a temporary proposal is given so as to enable the integration of more wind power. The authors suggest that if the energy carrier for part of the end users' space heating is switched from heating water to electricity (e.g., electric heat pumps (EHPs) can provide space heating in the domestic sector), the ratio of electricity to heating water load should be adjusted to optimize the power dispatch between cogeneration units and wind turbines, resulting in fuel conservation. With this proposal, existing infrastructures are made full use of, and no additional ones are required. Finally a numerical simulation is performed in order to illustrate both the technical and economic feasibility of the aforementioned proposal, under ongoing infrastructures as well as electricity and space heating tariff conditions without changing participants' benefits. The authors aim to persuade Chinese policy makers to enable EHPs to provide space heating to enable the integration of more wind power.
\end{abstract}


Keywords: electric heat pumps (EHPs); electric heating; coal-fired cogeneration; energy carriers; wind power integration

\section{Introduction}

In order to meet the abundant space heating demand efficiently, district heating and coal-fired cogeneration units equipped with extraction-condensing steam turbines have been encouraged. They have seen a high penetration in Northern China [1-3], which has $17.6 \%$ of the total fossil fuel power plants with rapid growth up to $18.5 \%$. Northern China covers the northwest grid, north grid and southeast grid $[4,5]$. This can be attributed to the fuel conservation which may be obtained based on coal-fired cogeneration units [6]. In fact it seems to make sense, because coal has always been the dominant primary fuel in the Chinese power sector [7,8]. Under this condition, heating water is generally treated as an energy carrier for space heating purposes by Chinese policy makers, so that large scale heat-metering and remote control are carried out for energy conservation $[9,10]$. Because coal-fired cogeneration units have to generate electrical power along with thermal power according to $[11,12]$, practical cogeneration units in Northern China are only allowed by Chinese policy makers to generate electricity in terms of heating water production. However, power balancing may cause a situation where wind power needs to be curtailed in the electric power grid such as in regions like Inner Mongolia [3]. This is at odds with the current power dispatch policy in the electric power grid of China, which emphasizes that utilization of wind power should be a priority $[5,13]$, while the mass introduction of wind power has been available and seems powerful during winter nights [14,15]. With regard to the aforementioned situation in Northern China, it is generally suggested that more transmission infrastructure should be constructed to accommodate the surplus wind power, but this solution relies heavily on the policy framework, capital investment, etc., and cannot be implemented immediately. In addition, surplus wind power mostly occurs during off-peak load at night, which could mainly be attributed to the opposite fluctuation patterns of wind power and grid load [14,15] and makes the new transmission infrastructure not economical enough.

Some promising alternative technologies appear to facilitate the wind power integration, including pumped storage, electric vehicles, heating storage, flexible district heating and cogenerations, as well as electric heat boilers and heat pumps [3,16-19]. Besides, some energy model review works have been carried out so as to enable more integration of renewable energy [20-22]. The impact of various characteristics of electricity and heating demand on optimal configuration of a microgrid is revealed in [23]. In particular, EHPs are recommended as one promising alternative solution in both Europe and Japan in [19,24-30], because they help to change the characteristics of end use of electricity and heat.

Based on the aforementioned works, firstly the authors suggest that a serious divergence may exist in the ratio of electrical to thermal energy between end users' demand and the cogeneration units' production during off-peak load at night that prevents more wind power integration (here, off-peak load at night means from 0:00 7:00 o'clock) instead of inadequate transmission infrastructures. In addition, end users' load patterns of electricity and space heating have not been considered to be adjustable for optimizing the dispatch between cogenerations and wind turbines, which can help to 
relieve the link between the electrical and thermal power. Finally because neither performance of cogeneration units nor the market mechanism is like that described in [16-30], it is worth discussing both the technical and economic feasibility of mass introduction of EHPs in Northern China.

In this article, the authors suggest a possible way to adjust the end users' electrical and thermal energy consumption during off-peak load at night without new investments. First, existing various air-conditioners (or EHPs) which have been installed in end-users' site should be enabled to provide space heating in the domestic sector, so that the energy carriers for part of the end users' space heating can be switched from heating water to electricity. Thus no supplemental investment is needed. Secondly, what about the adjustable load pattern in the residential sector? Thirdly, gross electrical and thermal energy production seem to be adjusted so as to optimize the dispatch between coal-fired cogeneration facilities and wind turbines, which depends on the practical performance of cogenerations in Northern China and results in a critical coefficient of performance (COP) of electric heat pumps introduced. Finally, a numerical simulation is performed to illustrate the feasibility of the authors' proposal. This article is configured in six sections. Besides this section that serves as Introduction, the serious divergence of the ratio of electrical to thermal energy between the end users' demand and the cogeneration production is covered in Section 2. The authors' proposal is put forth in Section 3. Section 4 is devoted to a numerical simulation. Results and Discussion are given in Section 5. Finally, Conclusions are drawn in Section 6.

\section{Performance of End Users and Cogenerations}

In accordance with the present Chinese policy framework: (1) Heating water is generally adopted for the end users' space heating; (2) Cogeneration units have to generate corresponding electricity in terms of heating water. These two issues directly result in a divergence in the ratio of electrical to thermal energy between the end users' demand and the cogenerations' production during off-peak load at night, which to some extent has a negative impact on wind power integration [15].

\subsection{End Users' Load}

The authors have developed experiment projects [31,32], through which field investigation of 10 households could be conducted in Northern China. Thus both electricity for electric appliances and thermal energy consumption values for space heating purpose have been obtained and are shown in Figures 1-2, respectively, which correspond to about 10 households from 0:00 7:00 o'clock in a day. The ratio of electricity to thermal energy consumption is shown in Figure 3. H1 H10 means household 1 10.

As described in Figures 1-3, little electricity consumption appears, in contrast to much more thermal energy consumption, which results in relatively low values in the ratio of electricity to thermal energy consumption. The present energy market regulations in China result in the existence of two main separate energy service infrastructures. Electric power grid is for electricity service and the district heating networks are for heating service. In addition, the prices of these two energy carriers are regulated by the government. 
Figure 1. Electricity consumption of 10 households for electric appliances.

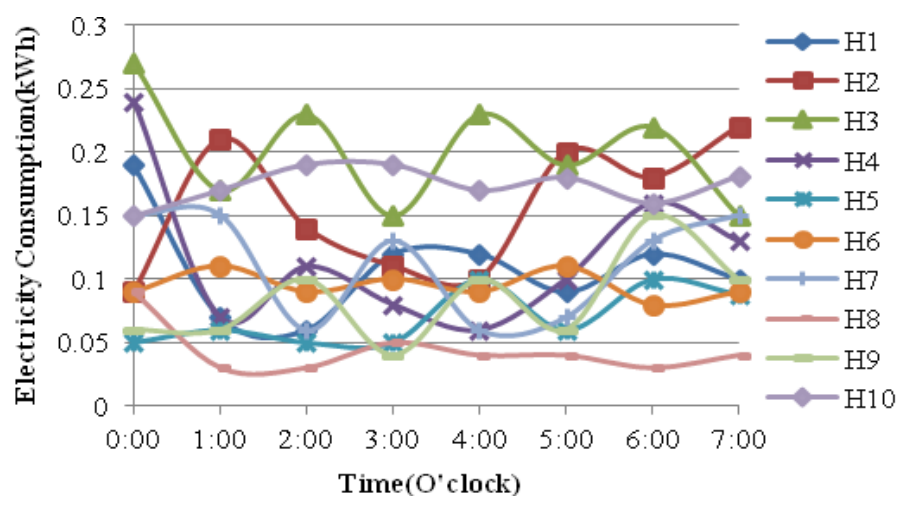

Figure 2. Thermal energy consumption of 10 households for space heating.

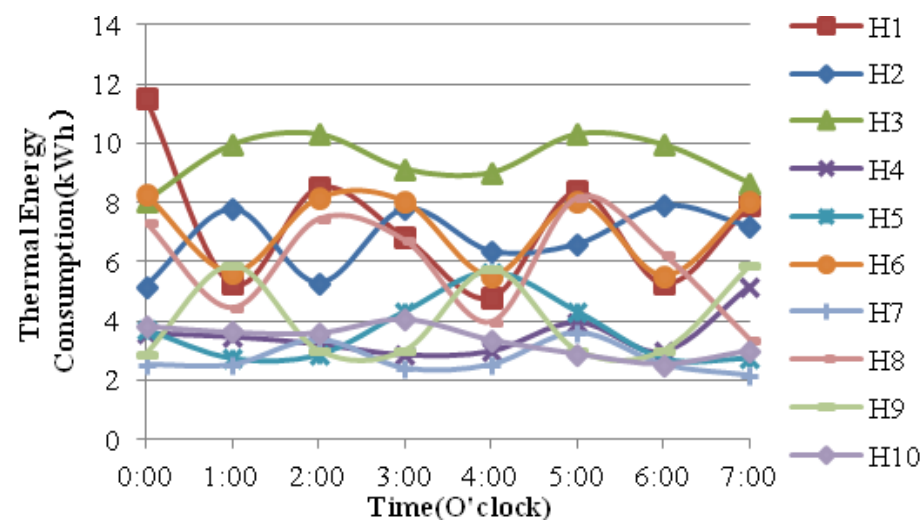

Figure 3. Ratio of electricity to thermal energy consumption of 10 households.

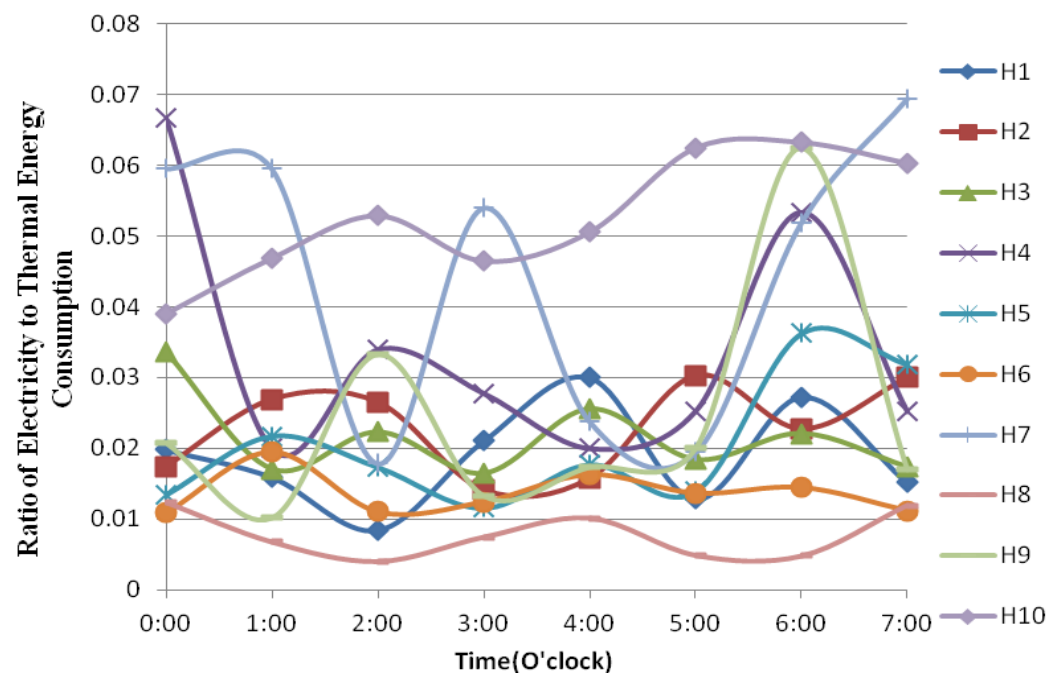

Currently the electricity cost for space heating purposes seems much more expensive than heating water. With regard to Figures 1-3, it can be explained as follows: during the night most end users in the domestic sector are asleep, so little electricity is consumed while abundant heating water is needed for space heating purposes. The small electricity load could be covered by electrical power generated from cogeneration units, while the abundant heating water was covered by thermal power generated from cogenerations. It is emphasized that 10 households seem insufficient, and only reveal the authors' idea. 


\subsection{Cogenerations' Production}

The authors have established remote metering and dispatch infrastructures in the electric power grid of Northern China [31], so that a PQ-chart (electrical power versus thermal power chart) for a condensing-extraction cogeneration C135/N150-13.24 unit is achieved. This PQ-chart is shown in Figure 4 and can be formulated as Equations $(1,2)$.

Figure 4. PQ-chart of C135/N150-13.24.

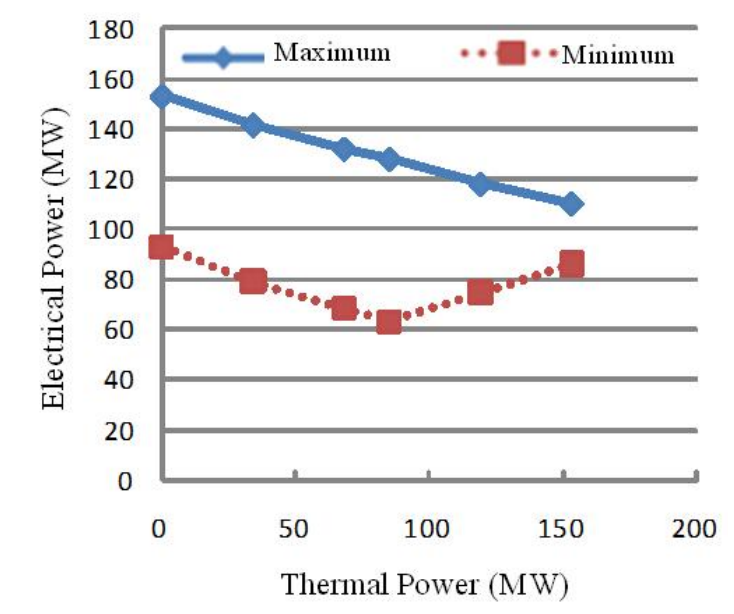

$$
\begin{aligned}
& P^{\max }=-0.279 \cdot Q+151.9 \quad 0 \leq Q \leq 153 \\
& P^{\min }=\left\{\begin{array}{lr}
-0.344 \cdot Q+92.06 & 0 \leq Q<85 \\
0.33 \cdot Q+35.32 & 85 \leq Q \leq 153
\end{array}\right.
\end{aligned}
$$

where $P^{\max }$ and $P^{\min }$ are the maximum and minimum electrical power, respectively, versus a certain thermal power $Q$ generated. According to the PQ-chart of Figure 4, the electrical power relies on thermal power, so the ratio of electrical to thermal power is limited within a certain range. This ratio is shown in Figure 5.

Figure 5. Ratio of electrical to thermal power of C135/N150-13.24.

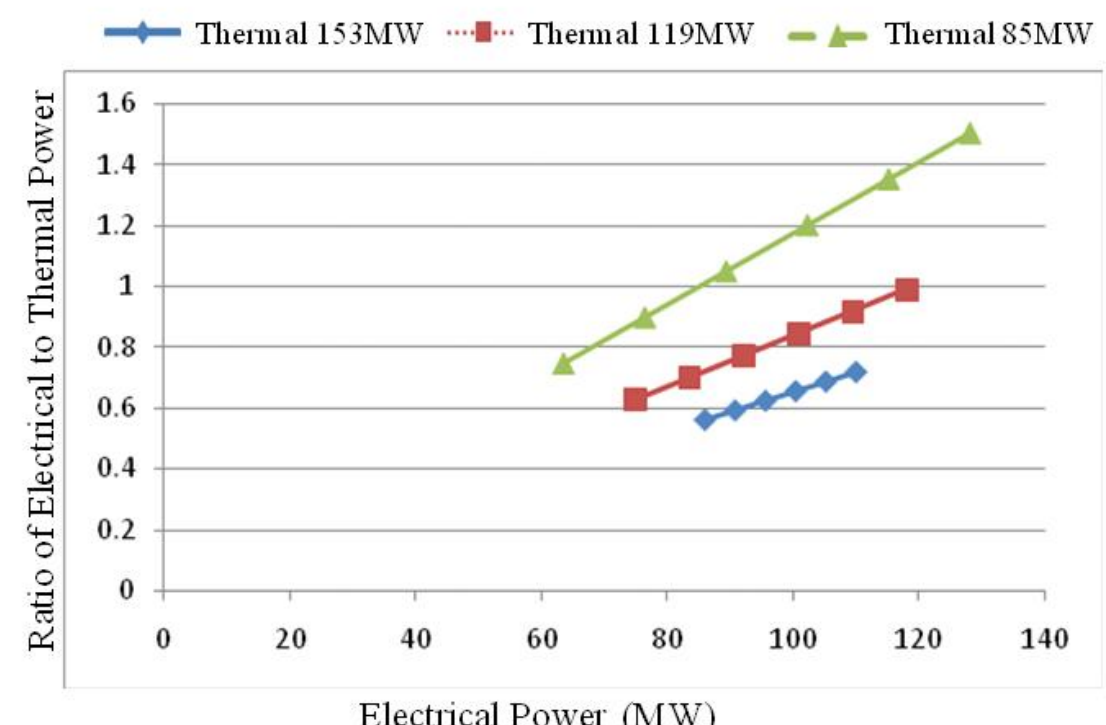

Electrical Power (MW) 
It can be found that the more thermal power generated, the lower is the ratio of electrical to thermal power generated. It can be seen that this ratio of cogeneration in Figure 5 is much more than that of the end users in Figure 3. This can be attributed to the fact that the households' electrical energy consumption is separated from thermal energy consumption, which is different from that of cogeneration units' production. From Figures 3 and 5, it can be inferred that there is a considerable diversity between the end users' energy consumption and cogeneration facilities' production, even though it is only based on 10 households. It is deduced that as long as high penetration coal-fired cogeneration power is available, the electric power grid is rigid and wind power may be curtailed.

From the abovementioned investigation of both the end users and cogenerations, it can be found that heating water should not be treated as sole energy carrier for space heating purposes in Northern China, because it have a negative impact on the wind power integration.

\section{Proposal}

In Section 3, the authors suggest that both heating water and electricity should be used as energy carriers for space heating, so that part of the end users' space heating load could be switched from heating water to electricity. Thus the ratio of electricity to thermal load is changed and this leads to a new optimal dispatch scenario between cogeneration units and wind turbines. While cogeneration units' heating water is shaved, less electricity from cogeneration will be obtained and more wind power may be integrated.

With regard to the authors' proposal, three issues should be emphasized: (1) The authors' proposal is to be performed temporarily during off-peak load at night (e.g., 0:00 7:00), when most end users are asleep and are not so sensitive to thermal comfort; (2) All kinds of existing EHPs, including air source EHPs, geothermal EHPs, and water source EHPs can be used. Generally speaking, the coefficient of performance (COP) under electrical resistance heater mode is minimum and around 1 [19,24-28]. In China, air-conditioners (they can also perform in EHP mode for space heating) installed in the domestic sector for space cooling with mandatory minimum COP values above 3 [33], the authors' proposal seems to guarantee the COP of EHPs for space heating beyond 1 without much auxiliary investment; (3) Based on the emerging infrastructures such as smart grids, remote control on either heating water radiators or EHPs for end users' space heating in domestic sector is enabled $[9,10,31,32]$. The authors aim to persuade the Chinese policy makers from three aspects that:

1. Is it technically feasible according to the COP of present EHPs?

2. In 3.1, the authors formulate one optimization problem for a critical COP of EHPs cooperating with a single cogeneration to serve space heating, beyond which fuel conservation is achieved.

3. Is it of fuel conservation while introducing EHPs?

4. In 3.2, the authors formulate the other new optimization problem so as to calculate the fuel conservation from more wind power integration while COP is in the range of 1.0 6.0. This is separated from the optimization problem for a critical COP of EHPs abovementioned.

5. Is it economically feasible?

In Section 3.3, the authors are devoted to economic feasibility of this proposal based on present policy framework in China. In this article, the unit for power is set as MW, and for energy as MWh. 


\subsection{Mathematic Model Regarding Critical COP of EHPS}

Currently original end users' space heating load $Q_{\text {Load }}^{*}(\mathrm{MW})$ is assumed to be thoroughly served by cogeneration units' thermal power production (heating water), which is formulated as Equation (3). The original end users' electricity load $P_{\text {Load }}^{*}$ (MW) for electric appliances is provided by the cogeneration units' electrical power production, which is formulated as Equation (4). Both $Q_{\text {Load }}^{*}$ and $P_{\text {Load }}^{*}$ are the boundary conditions of this optimization model. Variables with subscript * mean performing under existing operation mode like Equations $(3,4)$ :

$$
\begin{gathered}
Q_{\text {Load }}^{*}=\sum_{i=1}^{I}\left(Q_{i}^{*} \cdot \eta_{i}^{q}\right) \\
P_{\text {Load }}^{*}=\sum_{i=1}^{I}\left(P_{i}^{*} \cdot \eta_{i}^{e}-L_{i}^{*}\right) \cdot \eta_{G R D}
\end{gathered}
$$

where $Q_{i}^{*}(\mathrm{MW})$ is the thermal power generated from the $i$ th cogeneration; $\eta_{i}^{q}$ is the heating efficiency of the $i$ th cogeneration, $0.97 ; P_{i}^{*}$ (MW) is the minimum electrical power generated from the $i$ th cogeneration; $\eta_{i}^{e}$ is electricity efficiency of the $i$ th cogeneration, $0.95 ; L_{i}^{*}$ (MW) is the electricity consumption of the $i$ th cogeneration for circulating heating water, and formulated in Equation (5); $\eta_{G R D}$ is transmission efficiency of the electric grid (0.94 in [13]):

$$
L_{i}^{*}=Q_{i}^{*} \cdot E H R
$$

where EHR is the constant of circulating heating water, 0.03 [34]. The gross original fuel consumed by cogenerations $F_{C H P}^{*}(\mathrm{MWh})$ is formulated as Equation (6):

$$
F_{C H P}^{*}=\sum_{i=1}^{I} F_{i}^{*}=\sum_{i=1}^{I} T \cdot\left(k_{i} \cdot Q_{i}^{*}+m_{i} \cdot P_{i}^{*}+c_{i}\right)
$$

where $F_{i}^{*}(\mathrm{MWh})$ is the original fuel consumed by the $i$ th cogeneration; $T(\mathrm{~h})$ is the operating duration of cogeneration (hours); $k_{i}, m_{i}$ and $c_{i}$ are various unit constants of the $i$ th cogeneration respectively.

Compared with Equations (3-6) through which $Q_{\text {Load }}^{*}$ and $P_{\text {Load }}^{*}$ are served by cogeneration units only, the authors' new proposal is that part of the end users' space heating load $Q_{\text {Load }}^{*}$ should be served by EHPs consuming electrical power $P_{E H P}^{\wedge}(\mathrm{MW})$ as Equation (7), and electrical power consumed by EHPs is only from cogeneration as indicated by Equation (8):

$$
\begin{gathered}
Q_{\text {Load }}^{*}=\sum_{i=1}^{I}\left(Q_{i}^{\wedge} \cdot \eta_{i}^{q}\right)+C O P_{c r i}^{\wedge} \cdot P_{E H P}^{\wedge} \\
P_{\text {Load }}^{*}=\sum_{i=1}^{I}\left(P_{i}^{\wedge} \cdot \eta_{i}^{e}-Q_{i}^{\wedge} \cdot E H R\right) \cdot \eta_{G R D}-P_{E H P}^{\wedge}
\end{gathered}
$$

where $Q_{i}^{\wedge}(\mathrm{MW})$ is the new thermal power generated from the $i$ th cogeneration; $C O P_{c r i}^{\wedge}$ is the critical coefficient of performance (COP) of the corresponding EHPs; positive $P_{E H P}^{\wedge}(\mathrm{MW})$ is the electrical power consumed by the EHPs for space heating purpose; $P_{i}^{\wedge}(\mathrm{MW})$ is the new electrical power generated from the $i$ th cogeneration. New allowed minimum and maximum electrical power generated by the $i$ th cogeneration are $P_{i}^{\min ^{\wedge}}(\mathrm{MW})$ and $P_{i}^{\max }(\mathrm{MW})$ respectively, which are formulated as Equations $(9,10)$ respectively: 


$$
\begin{aligned}
& P_{i}^{\min ^{\wedge}}=l_{i}^{\min } \cdot Q_{i}^{\wedge}+n_{i}^{\min } \\
& P_{i}^{\max }=l_{i}^{\max } \cdot Q_{i}^{\wedge}+n_{i}^{\max }
\end{aligned}
$$

where $l_{i}^{\min }, n_{i}^{\min }, l_{i}^{\max }$ and $n_{i}^{\max }$ are various constants of the $i$ th cogeneration. The fuel consumption of the $i$ th cogeneration $\hat{F_{i}}(\mathrm{MWh})$ is formulated as Equation (11):

$$
F_{i}^{\wedge}=T \cdot\left(k_{i} \cdot Q_{i}^{\wedge}+m_{i} \cdot P_{i}^{\wedge}+c_{i}\right)
$$

where $P_{i}^{\wedge}$ is electrical power of the $i$ th cogeneration (MW). Constraints are formulated as Equations (12-15):

$$
\begin{gathered}
0 \leq Q_{i}^{\wedge} \leq Q_{i}^{\max } \\
P_{i}^{\min ^{\wedge}} \leq P_{i}^{\wedge} \leq P_{i}^{\max } \\
F_{C H P}^{\wedge}=\sum_{i=1}^{I} F_{i}^{\wedge}=\sum_{i=1}^{I} T \cdot\left(k_{i} \cdot Q_{i}^{\wedge}+m_{i} \cdot P_{i}^{\wedge}+c_{i}\right) \\
0 \leq P_{E H P}^{\wedge} \\
F_{C H P}^{\wedge} \leq F_{C H P}^{*}
\end{gathered}
$$

where $Q_{i}^{\max }(\mathrm{MW})$ is the allowed maximum thermal power generated from the $i$ th cogeneration. $F_{C H P}^{\wedge}$ $(\mathrm{MWh})$ is the gross fuel consumption. This optimization problem is devoted to finding the critical COP of EHPs $C O P_{c r i}^{\wedge}$, above which fuel conservation can be achieved solely by adjusting cogenerations' electrical and thermal power generated. In this optimization problem, the objective function is formulated as Equation (17):

$$
\text { Minimum: } C O P_{c r i}^{\wedge}
$$

\subsection{Mathematic Model for Fuel Conservation}

A considerable number of wind turbines have been installed in Northern China [35,36]. Besides, there exist high penetration coal-fired cogeneration units whose heating water production is accompanied by minimal electricity production. Compared with Equations (3-6) through which $Q_{\text {Load }}^{*}$ and $P_{\text {Load }}^{*}$ are served by cogeneration units only, the authors' proposal is that part of the end users' space heating load $Q_{\text {Load }}^{*}$ should be served by EHPs consuming electrical power $P_{E H P}(\mathrm{MW})$ as Equation (18), and more wind power $P_{W I N D}(\mathrm{MW})$ may be utilized as Equation (19):

$$
\begin{gathered}
Q_{\text {Load }}^{*}=\sum_{i=1}^{I}\left(Q_{i} \cdot \eta_{i}^{q}\right)+C O P \cdot P_{E H P} \\
P_{\text {Load }}^{*}=\sum_{i=1}^{I}\left(P_{i} \cdot \eta_{i}^{e}-Q_{i} \cdot E H R\right) \cdot \eta_{G R D}+P_{W I N D} \cdot \eta_{W I N D}-P_{E H P}
\end{gathered}
$$

where $Q_{i}(\mathrm{MW})$ is the new thermal power generated from the $i$ th cogeneration; COP is the coefficient of performance of the corresponding EHPs; positive $P_{E H P}(\mathrm{MW})$ is the electrical power consumed by the EHPs for space heating purpose; $P_{i}(\mathrm{MW})$ is the new electrical power generated from the $i$ th cogeneration; $P_{W I N D}(\mathrm{MW})$ is the additional wind power utilized; $\eta_{W I N D}$ is the efficiency of the wind 
turbines (0.95). New minimum and maximum electrical power generated by the $i$ th cogeneration are $P_{i}^{\min }(\mathrm{MW})$ and $P_{i}^{\max }(\mathrm{MW})$ respectively, which are formulated as Equations $(20,21)$ respectively:

$$
\begin{gathered}
P_{i}^{\min }=l_{i}^{\min } \cdot Q_{i}+n_{i}^{\min } \\
P_{i}^{\max }=l_{i}^{\max } \cdot Q_{i}+n_{i}^{\max }
\end{gathered}
$$

where $l_{i}^{\min }, n_{i}^{\min }, l_{i}^{\max }$ and $n_{i}^{\max }$ are various constants of the $i$ th cogeneration. The new fuel consumption of the $i$ th cogeneration $F_{i}(\mathrm{MWh})$ is formulated as Equation (22):

$$
F_{i}=T \cdot\left(k_{i} \cdot Q_{i}+m_{i} \cdot P_{i}+c_{i}\right)
$$

where $P_{i}$ is new electrical power of the $i$ th cogeneration (MW). Constraints are as Equations (23-26):

$$
\begin{gathered}
0 \leq Q_{i} \leq Q_{i}^{\max } \\
P_{i}^{\min } \leq P_{i} \leq P_{i}^{\max } \\
F_{C H P}=\sum_{i=1}^{I} F_{i}=\sum_{i=1}^{I} T \cdot\left(k_{i} \cdot Q_{i}+m_{i} \cdot P_{i}+C_{i}\right) \\
0 \leq P_{E H P}
\end{gathered}
$$

where $Q_{i}^{\max }(\mathrm{MW})$ is the new allowed maximum thermal power generated from the $i$ th cogeneration. $F_{C H P}(\mathrm{MWh})$ is the new gross fuel consumption.

The objective function is to maximize the fuel conservation $\Delta F$, which is formulated as Equation (27):

$$
\text { Maximum: } \Delta F=\frac{F_{C H P}^{*}-F_{C H P}}{F_{C H P}^{*}} \times 100 \%
$$

\subsection{Mathematic Model Regarding Economy}

The authors' proposal may bring about economic benefits in the following aspects after fuel conservation is achieved by application of Equations (18-27). Firstly, participants, including end users, cogeneration facilities and the electric grid may obtain delta benefits compared with the current mode of operation. Secondly, after participants' delta benefits are compensated in accordance with the current operation mode, the tariff of auxiliary wind power utilized will be deduced. Any changes to the present policy are avoided by authors. Thus participants' delta benefits and tariffs of auxiliary wind power utilized are discussed in accordance with present policy framework in China [37,38] which results in the power and cash flow shown in Figure 6.

Because electricity is introduced for space heating purposes, the delta expense of end users $\Delta C_{E N D}$ is formulated as Equation (28). In addition, because fuel consumption and generation change, the delta profit of cogeneration $\Delta P_{C H P}$ changes as Equation (29). Furthermore, because electricity transmitted through electric power grid varies, the delta profit of the grid $\triangle P_{G R D}$ is formulated as Equation (30). $\varepsilon_{e}^{\text {wind }}$ is formulated as Equation (31) on the condition that all participants' benefits are unchanged:

$$
\Delta C_{E N D}=T \cdot\left(C O P \cdot P_{E H P} \cdot \varepsilon_{q}-P_{E H P} \cdot \varepsilon_{e}^{\text {end }}\right)
$$




$$
\begin{gathered}
\Delta P_{C H P}=\left(F_{C H P}^{*}-F_{C H P}\right) \cdot \varepsilon_{f}+T \cdot \sum_{i=1}^{I}\left(Q_{i}-Q_{i}^{*}\right) \cdot \eta_{i}^{q} \cdot \varepsilon_{q}+ \\
T \cdot\left(\sum_{i=1}^{I}\left(P_{i} \cdot \eta_{i}^{e}-Q_{i} \cdot E H R\right)-\sum_{i=1}^{I}\left(P_{i}^{*} \cdot \eta_{i}^{e}-Q_{i}^{*} \cdot E H R\right)\right) \cdot \varepsilon_{e}^{g r d} \\
\Delta P_{G R D}=T \cdot\left(\sum_{i=1}^{I}\left(P_{i} \cdot \eta_{i}^{e}-Q_{i} \cdot E H R\right)-\sum_{i=1}^{I}\left(P_{i}^{*} \cdot \eta_{i}^{e}-Q_{i}^{*} \cdot E H R\right)\right) \cdot \\
\left(\eta_{G R D} \cdot \varepsilon_{e}^{e n d}-\varepsilon_{e}^{\text {grd }}\right) \\
\varepsilon_{e}^{\text {wind }}=\frac{T \cdot \sum_{i=1}^{I}\left(Q_{i} \cdot \eta_{i}^{q} \cdot \varepsilon_{q}\right)+T \cdot\left(P_{\text {sum }}^{*}+P_{E H P}\right) \cdot \varepsilon_{e}^{\text {end }}-F_{C H P} \cdot \varepsilon_{f}-P_{C H P}-P_{G R D}-\Delta C_{E N D}}{P_{W N D} \cdot \eta_{W N D}}
\end{gathered}
$$

where $P_{C H P}$ is the cogenerations' profit formulated as Equation (32); $P_{G R D}$ is the profit of the electric grid and is formulated as Equation (33):

$$
\begin{gathered}
P_{C H P}=T \cdot \sum_{i=1}^{I}\left(P_{i}^{*} \cdot \eta_{i}^{e}-Q_{i}^{*} \cdot E H R\right) \cdot \varepsilon_{e}^{g r d}+T \cdot \\
\sum_{i=1}^{I} Q_{i}^{*} \cdot \eta_{i}^{q} \cdot \varepsilon_{q}-F_{C H P}^{*} \cdot \varepsilon_{f} \\
P_{G R D}=T \cdot \sum_{i=1}^{I}\left(P_{i}^{*} \cdot \eta_{i}^{e}-Q_{i}^{*} \cdot E H R\right) \cdot\left(\eta_{G R D} \cdot \varepsilon_{e}^{e n d}-\varepsilon_{e}^{g r d}\right)
\end{gathered}
$$

Figure 6. Schematic of power and cash flow.

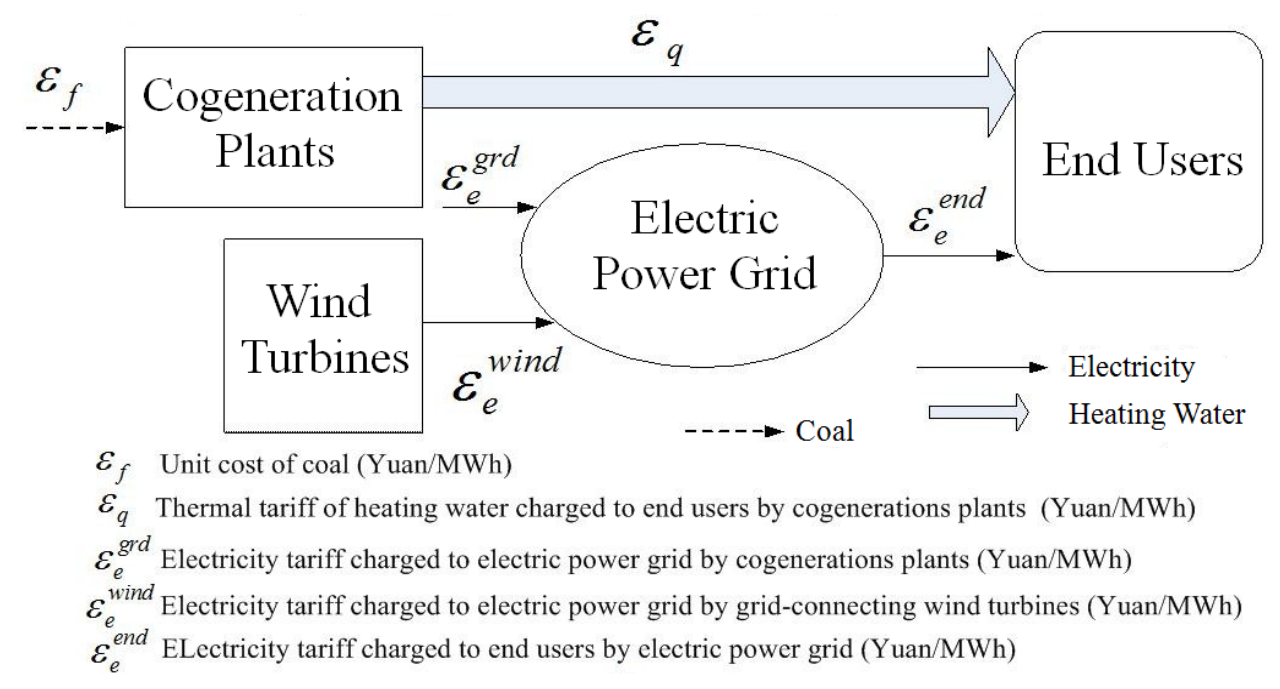

\section{Numerical Simulation}

With regard to the $\mathrm{C} 135 / \mathrm{N} 150-13.24$ condensing-extraction cogeneration unit, constants $l_{i}^{\max }$ and $n_{i}^{\max }$ are shown as Equation (1); constants $l_{i}^{\min }$ and $n_{i}^{\min }$ are as given by Equation (2); constants $k_{i}, m_{i}$ and $c_{i}$ are as shown in Equation (34):

$$
F=\left\{\begin{array}{ll}
0.73 \cdot Q+2.48 \cdot E+3.59 & 34 \leq Q<68 \\
0.66 \cdot Q+2.43 \cdot E+12.73 & 68 \leq Q<85 \\
0.73 \cdot Q+2.42 \cdot E+8.11 & 85 \leq Q<119 \\
0.59 \cdot Q+2.45 \cdot E+22.47 & 119 \leq Q<53
\end{array}\right\}
$$


The electricity and heating water tariffs under the present policy framework are shown in Table 1.

Table 1. Present heating water and electricity tariffs.

\begin{tabular}{lllll}
\hline & $\varepsilon_{e}^{\text {end }}$ & $\varepsilon_{e}^{\text {grd }}$ & $\varepsilon_{q}$ & $\varepsilon_{f}$ \\
\hline Tariff (Yuan/MWh) & 500 & 300 & 100 & 100 \\
\hline
\end{tabular}

1. $C O P_{c r i}$ is calculated in the cases of a single cogeneration being available, so that economic dispatch influence can be avoided. For calculating $C O P_{c r i}$, the thermal load $Q_{\text {Load }}^{*}$ is set as $153 \mathrm{MW}, 119 \mathrm{MW}$ and $85 \mathrm{MW}$, respectively. In addition, the electrical load $P_{\text {Load }}^{*}$ is set as various values between the allowed minimum and maximum electrical power generated under a certain $Q_{\text {Load }}^{*}, T=1(\mathrm{~h})$.

2. The results of $\Delta F, \varepsilon_{e}^{\text {wind }}, \Delta C_{E N D}, \Delta P_{C H P}$ and $\Delta P_{G R D}$ are calculated in the case assuming there are 100 MW of surplus wind power and twelve C135/N150-13.24 extraction-condensing cogeneration units available. Original electrical load $P_{\text {Load }}^{*}$ is set as $878 \mathrm{MW}$, original thermal load $Q_{\text {Load }}^{*}$ is set as $1781 \mathrm{MW}$, and $T=1$ (h). Under the original operation mode, $153 \mathrm{MW}$ heating water and 85.9 MW electricity are supposed to be generated from each cogeneration unit, all of which meet the $Q_{\text {Load }}^{*}$ and $P_{\text {Load. }}^{*} 100 \mathrm{MW}$ wind power is abandoned. Nonlinear Programming (NLP) is performed with GAMS ${ }^{\odot}$. It is explained that during off-peak load at night 0:00 7:00 o'clock, $100 \mathrm{MW}$ wind power is about $11.3 \%$ of $878 \mathrm{MW}$ electrical load, which is a rational assumption in the practical electric power grid of Northern China [3]. In addition, COP of EHPs is set $1.0 \sim 6.0$ for numerical simulation.

\section{Results and Discussion}

\subsection{Critical COP of EHPS}

Figure 7 shows the value of $C O P_{c r i}^{\wedge}$ at different thermal and electricity loads. $C O P_{c r i}^{\wedge}$ ranges around $3.3 \sim 3.8$, indicating that if $C O P<C O P_{c r i}^{\wedge}$, there is no fuel conservation, and if $C O P \geq C O P_{c r i}^{\wedge}$, there exists fuel conservation.

Figure 7. Critical COP of EHPs for fuel conservation.

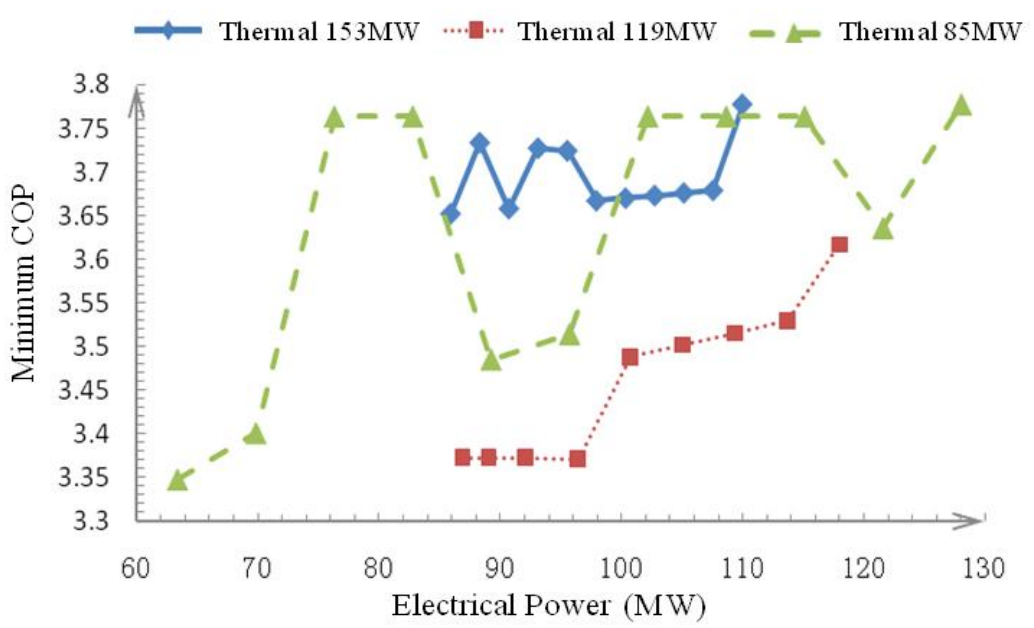




\subsection{Fuel Conservation and Economic Feasibility}

Both fuel conservation and economic feasibility are related to the COP of the EHPs used. COP is set in the range of 1.0 6.0 for numerical simulation. Generally speaking, the higher the outdoor temperature the higher $C O P$ is. $C O P$ of air-conditioners in China is usually considered under 1.0 3.0, and it is convenient to use according to the authors' proposal. $C O P$ of either geothermal EHPs or water source EHPs is around 4.0 6.0. It is emphasized that $C O P_{c r i}^{\wedge}$ in Section 5.1 is separated from $C O P$ here. Because the authors' proposal is only focused on enabling more wind power integration during off-peak load at night 0:00 7:00 o'clock, the tradeoff of choosing EHPs should be considered in practice.

\subsubsection{Delta Benefits of Participants}

Figure 8 shows the change of the benefits of the participants for different values of $C O P$. When $C O P$ is lower than $5, \Delta C_{E N D}$ is lower than zero, meaning that end users are charged more. According to the authors' proposal a corresponding subsidy should be given to these end users. When COP is more than $5, \Delta C_{E N D}>0$, and these end users are charged less because of the high COP of EHPs. These end users are supposed to refund the auxiliary profit for deducing the wind power tariff. In Figure 8, when delta benefits of cogenerations and electric power grid are $\Delta P_{C H P}<0, \Delta P_{G R D}<0$, they should be provided a corresponding subsidy so as to keep profits unchanged. Otherwise, if $\Delta P_{C H P}>0, \Delta P_{G H D}>0$, they should refund any additional profits.

Figure 8. Delta benefits of participants.

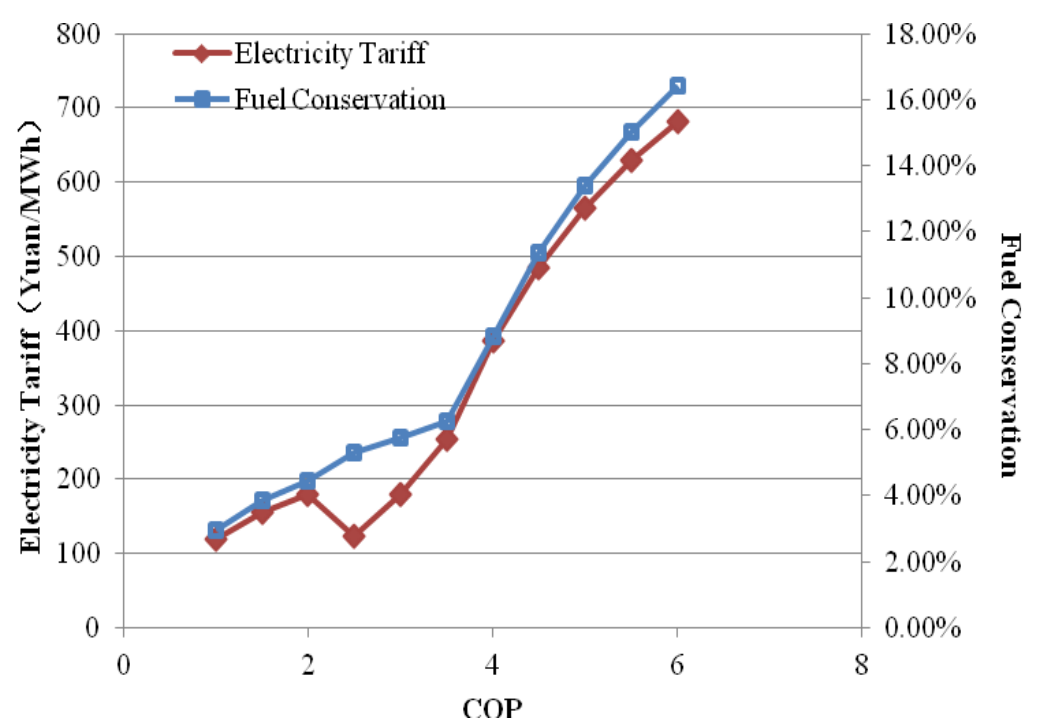

\subsubsection{Fuel Conservation and Tariff of More Wind Power Integrated}

In Figure 9, fuel conservation $\triangle F$ increases with $C O P$ which is in the range of 1.0 6.0. The slope of the fuel conservation curve increases sharply when $C O P$ is larger than the value of $C O P_{c r i}^{\wedge}$ shown in Figure 7 (3.3 3.8). Here, $C O P_{c r i}^{\wedge}$ works as a critical value with regard to the $C 135 / \mathrm{N} 150-13.24$ cogeneration unit. While $C O P$ is below $C O P_{c r i}^{\wedge}$, the fuel conservation obtained is attributed to more wind power integration only; it is about $3.0 \% \sim 6.2 \%$. If $C O P$ is beyond $C O P_{c r i}^{\wedge}$, fuel conservation is 
about $8.8 \% \sim 16.4 \%$ which will be from both wind power and cogeneration units generating more electricity and less heating water. If keeping participants' benefit unchanged, a positive electricity tariff of wind power $\varepsilon_{e}^{\text {wind }}$ can be observed in Figure 9. The more wind power integrated is able to receive a competitive electricity rate, in contrast to the present electricity rate of wind power set as 510, 540, 580, 600 (Yuan/MWh).

Figure 9. Fuel conservation and electricity tariff of wind turbines.

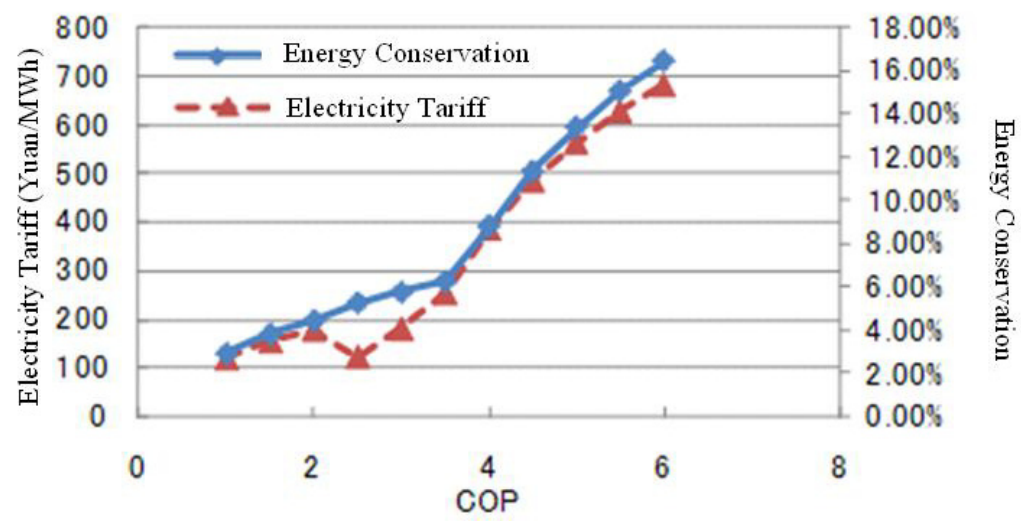

In Equation (31), $\varepsilon_{f}$ has something to do with $\varepsilon_{e}^{\text {wind }}$, so in Figure 10, a sensitivity analysis considering the price of coal $\varepsilon_{f}$ has been performed, which reveals that $\varepsilon_{e}^{\text {wind }}$ goes higher with increasing $\varepsilon_{f}$ and COP of EHPs. Because $\varepsilon_{e}^{\text {wind }}$ arises from the fuel conservation $\Delta F$, both more $\varepsilon_{f}$ and higher COP result in higher $\varepsilon_{e}^{\text {wind }}$.

Figure 10. Sensitivity analysis towards the price of coal.

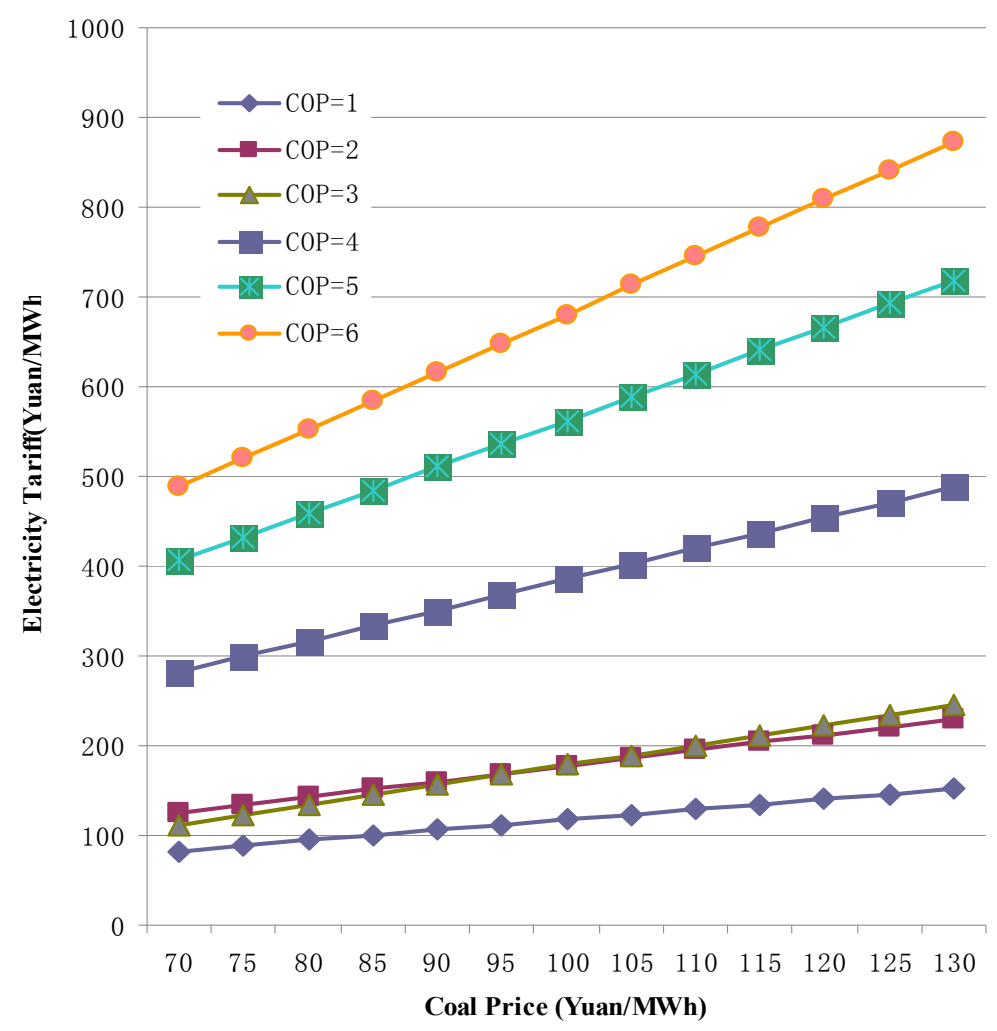


In Northern China currently wind farms with $49.5 \mathrm{MW}$ capacity are popular because they can be easily approved by the provincial government instead of the China National Energy Administration, so according to the numerical simulation, one wind farm and six cogeneration units should cooperate with each other to serve the corresponding end users in accordance with the authors' proposal, so that the curtailment of wind power can be avoided. This seems dependent on the installation capacity of cogeneration units.

\section{Conclusions}

In Northern China, a large amount of wind power is lost during the heating season. This arises from: (1) a serious divergence in the ratio of electrical to thermal energy between the end users' load and cogeneration units' production; (2) high penetration of coal-fired cogeneration units equipped with extraction-condensing steam turbines; (3) abundant wind turbines installed. The authors propose that the use of heating water as energy carrier for space heating should be shaved and the amount of electricity used as an energy carrier for space heating should be increased, which adjusts the ratio of electrical to thermal energy consumption on the end users' side. With adjusted thermal and electrical load constraints, a new optimal dispatch would be performed. A numerical study on the feasibility of the authors' proposal is carried out and the following results are obtained:

1. While single cogeneration itself and EHPs cooperate to serve space heating, there exists a critical COP of EHPs, beyond which fuel conservation is achieved. For a C135/N150-13.24 extraction-condensing cogeneration, this critical $C O P\left(C O P_{c r i}^{\wedge}\right)$ is around 3.3 3.8.

2. If $C O P$ of EHPs is set as $1.0 \sim 6.0$, while $C O P$ is below $C O P_{c r i}^{\wedge}$, fuel conservation arises from more wind power integration only, it is about $3.0 \% \sim 6.2 \%$; while $C O P$ is beyond $C O P_{c r i}^{\wedge}$, additional fuel conservation can be achieved due to the cooperation of CHP and EHPs besides wind power, it is about $8.8 \% \sim 16.4 \%$.

3. While EHPs are introduced for space heating, the end users are charged more if COP is below 5, and charged less if $C O P$ is above 5 . In addition, the economic benefits of both cogeneration facilities and the electric grid change following the authors' proposal. It is also observed that if all participants' economy benefits are kept unchanged, positive and competitive electricity tariff of wind power is achievable, which is about 119.3 682.5 (Yuan/MWh).

The key point of the authors' proposal is devoted to improving the electricity-heat ratio through the use of end-users' electric heat pumps.

\section{Acknowledgments}

The authors would like to acknowledge the grant from the 2012 Research Funds (No. 522023120017, No. 522023120018) by State Grid of the People's Republic of China.

\section{References}

1. Cai, W.G.; Wu, Y.; Zhong, Y.; Ren, H. China building energy consumption: Situation, challenges and corresponding measures. Energy Policy 2009, 37, 2054-2059. 
2. Li, Y.; Fu, L.; Zhang, S.G.; Jiang, Y.; Zhao, X.L. A new type of district heating method with co-generation based on absorptionheat exchange (co-ah cycle). Energy Convers. Manag. 2011, 52, $1200-1207$.

3. Liu, W.; Lund, H.; Mathiesen, B.V. Large-Scale integration of wind power into the existing Chinese energy system. Energy 2011, 36, 4753-4760.

4. Energy Research Institute. Technology Roadmaps-China Wind Energy Development Roadmap 2050. Available online: http://www.iea.org/publications/freepublications/publication/ china_wind.pdf (accessed on 27 August 2012).

5. Kat, C. Integration of Renewables-Status and Challenges in China. Available online: http://www. iea.org/publications/freepublications/publication/Integration_of_Renewables.pdf (accessed on 27 August 2012).

6. Mircea, C.; Mavina, B. Regarding the greenhouse gas emissions of thermopower plants. Energy Convers. Manag. 2002, 43, 2135-2144.

7. Cai, W.J.; Wang, C.; Liu, W.L.; Mao, Z.W.; Yu, H.C.; Chen, J.N. Sectoral analysis for international technology development and transfer: Cases of coal-fired power generation, cement and aluminium in China. Energy Policy 2009, 37, 2283-2291.

8. Partridge, I.;Gamkhar, S. The role of offsets in a post-Kyoto climate agreement: The power sector in China. Energy Policy 2010, 8, 4457-4466.

9. Liu, L.B.; Fu, L.; Jiang, Y.; Guo, S. Major issues and solutions in the heat-metering reform in China. Renew. Sust. Energy Rev. 2010, 15, 673-680.

10. Liu, L.B.; Fu, L.; Jiang, Y.; Guo, S. Maintaining uniform hydraulic conditions with intelligent on-off regulation. Build. Environ. 2010, 45, 2817-2822.

11. Lin, F.; Yi, J. Optimal operation of a CHP plant for space heating as a peak load regulating plant. Energy 2000, 25, 283-298.

12. Ummels, B.C.; Gibescu, M.; Pelgrum, E.; Wil, L.; Kling, M.; Brand, A.J. Impacts of wind power on thermal generation unit commitment and dispatch. IEEE Trans. Energy Convers. 2007, 22, $44-51$.

13. Li, L.; Tan, Z.F.; Wang, J.H.; Xu, J.; Cai, C.K.; Hou, Y. Energy conservation and emission reduction policies for the electric power industry in China. Energy Policy 2011, 39, 3669-3679.

14. Yu, D.Y.; Liang, J.; Han, X.S.; Zhao, J.G. Profiling the regional wind power fluctuation in China. Energy Policy 2011, 39, 299-306.

15. Yu, D.Y.; Zhang, B.; Liang, J.; Han, X.S. The influence of generation mix on the wind integrating capability of North China power grids: A modeling interpretation and potential solutions. Energy Policy 2011, 39, 7455-7463.

16. Mathiesen, B.V.; Lund, H. Comparative analyses of seven technologies to facilitate the integration of fluctuating renewable energy sources. IET Renew. Power Gener. 2009, 32, 190-204.

17. Tuohy, A.; O'Malley, M. Pumped storage in systems with very high wind penetration. Energy Policy 2011, 39, 1965-1974.

18. Kiviluoma, J.; Meibom, P. Influence of wind power, plug-in electric vehicles, and heat storages on power system investments. Energy 2009, 35, 1244-1255.

19. Meibom, P.; Kiviluoma, J.; Barth, R.; Brand, H.; Weber, C.; Larsen, H.V. Value of electric heat boilers and heat pumps for wind power integration. Wind Energy 2007, 10, 321-337. 
20. Connolly, D.; Lund, H.; Mathiesen, B.V.; Leahy, M. A review of computer tools for analysing the integration of renewable energy into various energy systems. Appl. Energy 2010, 87, 1059-1082.

21. Jebaraj, S.; Iniyan, S. A review of energy models. Renew. Sust. Energy Rev. 2006, 10, 281-311.

22. Foley, A.M.; ÓGallachóir, B.P.; Hur, J.; Baldick, R.; McKeogh, E.J. A strategic review of electricity systems models. Energy 2010, 35, 4522-4530.

23. Shigeru, B.; Hiroki, W.; Hiroshi, A. Impact of various characteristics of electricity and heat demand on the optimal configuration of a microgrid. Electr. Eng. Jpn. 2009, 169, 6-13.

24. Mancarella, P. Cogeneration systems with electric heat pumps: Energy-Shifting properties and equivalent plant modelling. Energy Convers. Manag. 2009, 50, 1991-1999.

25. Torekov, M.S.; Bahnsen, N.; Qvale, B. The relative competitive positions of the alternative means for domestic heating. Energy 2007, 32, 627-633.

26. Chua, K.J.; Chou, S.K.; Yang, W.M. Advances in heat pump systems: A review. Appl. Energy 2010, 87, 3611-3624.

27. Blarke, M.B.; Lund, H. Large-Scale heat pumps in sustainable energy systems: System and project perspectives. Therm. Sci. 2007, 11, 143-152.

28. Cockroft, J.; Kelly, N. A comparative assessment of future heat and power sources for the UK domestic sector. Energy Convers. Manag. 2006, 47, 2349-2360.

29. Minagata, A.; Kato, T.; Suzuoki, Y. A study on reverse power flow from home co-generation system. Trans. Inst. Electr. Eng. Jpn. B 2008, 91, 479-485.

30. Sugihara, H.; Tsuji, K. Energy conservation in urban areas. IEEJ Trans. Electr. Electron. Eng. 2008, 3, 10-14.

31. Long, H.Y.; Wu, K.; Zhao, Y.; Ma, J.W. An infrastructure and methodology for energy saving dispatch between wind turbines and cogenerations. China Patent 201010261188.7, 24 August 2010.

32. Long, H.Y.; Xu, R.L.; He, J.J. Incorporating the variability of wind power with electric heat pumps-energies. Energies 2011, 10, 1448-1762.

33. Lin, J.; Rosenquist, G. Stay cool with less work: China's new energy-efficiency standards for air conditioners. Energy Policy 2008, 36, 1090-1095.

34. Measurement \& Assessment for Energy Efficiency of Residential Buildings in China [in Chinese]. Available online: http://www.mohurd.gov.cn/zcfg/jsbwj_0/jsbwjjskj/200807/P020080703605488 120121.doc (accessed on 27 August 2012).

35. Han, J.Y.; Mol, A.P.J.; Lu, Y.L.; Zhang, L. Onshore wind power development in China: Challenges behind a successful story. Energy Policy 2009, 37, 2941-2951.

36. Liu, Y.Q.; Kokko, A. Wind power in China: Policy and development challenges. Energy Policy 2010, 38, 5520-5529.

37. Ma, C.; Cherni, J.A.; Kentish, J. Renewable energy policy and electricity market reforms in China. Energy Policy 2007, 35, 3616-3629.

38. Ngan, H.W. Electricity regulation and electricity market reforms in China. Energy Policy 2010, $38,2142-2148$.

(C) 2012 by the authors; licensee MDPI, Basel, Switzerland. This article is an open access article distributed under the terms and conditions of the Creative Commons Attribution license (http://creativecommons.org/licenses/by/3.0/). 